\title{
RESENHAS
}

REVIEWS

\section{RESPONSABILIDADE CIVIL DA ATIVIDADE MÉDICA NO CÓDIGO DE DEFESA DO CONSUMIDOR}

\author{
Octávio Luiz Motta Ferraz \\ Elsevier, Rio de Janeiro, 2009
}

Estela Waksberg Guerrini ${ }^{(*)}$

Não é preciso explicar a importância do estudo sobre a responsabilidade civil da atividade médica à luz do Código de Defesa do Consumidor: o próprio autor do livro já inicia sua obra lembrando que, mais de quinze anos depois da promulgação da lei consumeirista, a controvérsia sobre a aplicação das normas de responsabilidade civil previstas no Código sobre as atividades médicas ainda é presente. No mundo jurídico, ainda não é consenso o entendimento de que a relação que o paciente possui com as empresas que atuam na área da saúde é caracterizada como sendo de consumo e que, consequentemente, as normas consumeiristas - incluídas aí as normas de responsabilidade civil - se aplicam a essas relações.

Que o profissional de saúde deve ser responsabilizado somente se a sua culpa ficar comprovada, não há dúvidas. A polêmica surge quando se discute se as empresas ligadas à atividade médica podem ser responsabilizadas independente da existência de culpa, sendo que para essa indagação são encontradas, ao menos, três possíveis respostas: alguns entendem que a responsabilidade trazida no CDC seria sempre objetiva, ou seja, bastaria a comprovação da ação ou omissão, do dano e do nexo causal. Outros entendem que a responsabilidade continuaria sendo subjetiva, ou seja, a

\footnotetext{
(*) Mestranda em Direitos Humanos pela Faculdade de Direito da Universidade de São Paulo, Bacharel em Direito pela Faculdade de Direito da Universidade de São Paulo, advogada no Instituto Brasileiro de Defesa do Consumidor. E-mail: estela.guerrini@ gmail.com. Recebido em 16.3.09.
} 
depender da comprovação de culpa. E finalmente, para outros a responsabilidade seria subjetiva, mas com presunção relativa de culpa contra a empresa, ou seja, caberia à empresa a prova de que não agiu culposamente. É esse debate que motivou Octávio Luiz Motta Ferraz em sua pesquisa: a responsabilidade civil das empresas privadas de assistência à saúde perante o consumidor no que toca à atividade médica.

O autor divide sua obra em duas partes, e inicia com a abordagem sobre o regime da responsabilidade civil dos fornecedores de serviços, em geral, no Código de Defesa do Consumidor.

Explica que os deveres do fornecedor de um produto ou serviço passam pela segurança (garantia da inexistência de defeito no produto ou serviço), pela prestabilidade (garantia da inexistência de vício no produto ou serviço), e pela informação. Todos esses deveres precisam atender à proteção da vida, à saúde, à propriedade e aos interesses econômicos dos consumidores.

O capítulo 2 trata da responsabilidade pelo fato do serviço, e conceitua um produto ou serviço defeituoso da seguinte forma: "aquele cujo grau de periculosidade é incompatível com aquilo que razoavelmente deles se pode esperar, levando-se em consideração as circunstâncias relevantes que envolvem seu fornecimento e fruição". Conclui que a responsabilidade civil presente no CDC está sujeita a gradações, podendo ser mais subjetiva ou mais objetiva a depender das circunstâncias concretas, até porque "aquilo que razoavelmente" se espera pode depender de um determinado espaço e momento histórico. O autor lembra que a responsabilidade objetiva clássica exige apenas a configuração de uma ação ou omissão, de um dano e do nexo de causalidade, mas, em seu ponto de vista, a partir do momento em que o defeito também é exigido, a responsabilidade deixa de ser simplesmente objetiva, sem maiores discussões, mas também está longe de ser subjetiva, situando-se dentro de um espectro entre uma e outra a depender do caso concreto.

No capítulo 3 o autor traz à discussão a responsabilidade pelo vício do serviço, e lembra que é a natureza do prejuízo sofrido pelo consumidor que determina o regime de responsabilidade: se o prejuízo for econômico, as normas de responsabilidade pelo vício serão aplicadas; se houver danos à saúde ou à propriedade, serão aplicadas as normas de responsabilidade pelo defeito. O vício se dá quando o resultado concreto está aquém do resultado esperado, tomando como referência a natureza da atividade, o estado atual da técnica e a informação que pode ser prestada e a que foi efetivamente prestada. $\mathrm{O}$ autor conclui que a responsabilidade será mais objetiva quanto mais determinado for o dever do fornecedor de prestabilidade, ou quanto mais a obrigação for de resultado; de outro lado, a responsabilidade será mais subjetiva quanto maior for o dever de diligência, ou quanto mais a obrigação for de meio. 
O capítulo 4 discorre sobre a responsabilidade pelos vícios e defeitos de informação. O autor começa esclarecendo que o dever de informação está associado à segurança ou à prestabilidade do produto ou serviço, mas enquanto que os defeitos (produto ou serviço inseguro) e os vícios (produto ou serviço impróprio para consumo) são falhas instrínsecas, a falha de informação é extrínseca. Sendo uma das grandes conquistas do consumidor, o dever de informação existe para que o consumidor possa exercer a sua liberdade de escolha, para que os seus interesses econômicos estejam protegidos, e para a sua segurança. Conclui, ao final do capítulo, que a responsabilidade pelo dever de informação deixa menos dúvidas de que é objetiva do que a responsabilidade pelos vícios e defeitos intrínsecos. A presunção, nesse caso, é relativa, ou seja, salvo comprovação em contrário pelo fornecedor, pressupõe-se que a informação era disponível.

A segunda parte do livro trata especificamente do objeto de pesquisa proposto: o regime especial da responsabilidade médica das empresas no Código de Defesa do Consumidor. As perguntas que regem essa segunda parte do estudo são as seguintes: o que deve ser considerado defeito ou vício na prestação de serviços de saúde? Quem deve ser considerado fornecedor para efeito de atribuição de responsabilidade? A resposta a esta última pergunta pode estar nos hospitais, nas clínicas e nos laboratórios, mas também nas operadoras de planos de saúde. Com relação a estas últimas, apesar de muita contestação por parte dessas entidades, o Superior Tribunal de Justiça é unânime em entender pela sua responsabilidade por danos causados aos usuários por corretores de planos de saúde, médicos e demais prestadores de serviços de saúde.

O capítulo 1 da parte 2 busca explicar como é estruturado o sistema da assistência privada à saúde no Brasil. Em linhas gerais, o autor conclui que o sistema é caracterizado pela concentração do poder de organização dos serviços médicos em poucos planos de saúde, o que leva a uma mitigação da liberdade de escolha do consumidor, assim como a uma despersonalização dos serviços médicos.

No capítulo 2, são investigados os sujeitos passivos da responsabilidade civil por falhas no serviço médico e os fundamentos dessa responsabilidade. $\mathrm{O}$ autor indaga quem pode ser considerado fornecedor do serviço médico para efeitos de responsabilidade: os hospitais, clínicas e laboratórios, ou também as organizadoras (planos de saúde, cooperativas, sistema de autogestão e seguradoras)? No caso dos primeiros, que são prestadores diretos, haverá responsabilidade quando houver defeito ou vício na estrutura ou na organização da prestação de serviço. No caso de responsabilidade por ato de terceiro, o autor defende que o seu fundamento é "a possibilidade de adoção de medidas globais, ex ante e ex post, com vistas à diminuição, e não eliminação, dos incidentes danosos". Com relação à responsabilidade das organizadoras, o autor bem ilustra que a responsabilidade dessas en- 
tidades por falhas médicas é praticamente unânime nos tribunais, e o fundamento da responsabilidade ainda mais utilizado é a conhecida culpa in eligendo e culpa in vigilando. Em seu entendimento, no entanto, o melhor fundamento reside no fato de que as entidades atraem para si a responsabilidade pelas falhas médicas na medida em que tomam para si a organização dos serviços de saúde. Assim, conclui que a responsabilidade das empresas prestadoras diretas dos serviços de saúde, operadoras de planos de saúde e seguradoras seguem um modelo de responsabilidade fundado na relação direta de confiança com os consumidores e na capacidade relativa de minimizar os defeitos e riscos dos serviços médicos.

O capítulo 3 discorre sobre o defeito e do vício nas atividades médicas sob cinco aspectos. Na medicina diagnóstica, aborda a questão das falhas de diagnóstico decorrentes da atividade intelectual e distingue o erro escusável do erro grosseiro. Conclui que o instrumento mais importante para garantir os direitos dos consumidores é o dever de informação do fornecedor sobre os riscos normais e previsíveis, sendo que a omissão dessa informação constitui defeito na prestação do serviço. Na medicina cirúrgica, a principal conclusão a que chega o autor é que a responsabilidade do cirurgião resulta da omissão de esclarecimentos e do dever de informação, e não da obtenção ou não obtenção de um resultado específico, mesmo nos casos de cirurgia estética, também passível de riscos e imprevistos. Na anestesia, o autor conclui que a obrigação é de meio, já que há riscos e imprevistos, mas a responsabilização se dará quando as informações sobre os riscos não forem devidamente fornecidas ao consumidor. $\mathrm{Na}$ infecção hospitalar, a responsabilidade das instituições hospitalares restará configurada quando essa instituição não conseguir provar que tomou todas as medidas, de acordo com o que se entender estar disponível naquele determinado espaço e momento histórico, para reduzir os riscos de infecção; a obrigação é de meio, pois se entende que não é possível a eliminação completa de todos os riscos. Na transfusão de sangue, o autor defende que medidas podem e devem ser tomadas para reduzir o risco, mas é impossível eliminá-lo; cabe ao consumidor constatar o defeito e acionar a empresa que diretamente prestou-lhe um serviço, independente se a culpa foi efetivamente dessa empresa.

O último capítulo do livro trata do defeito e do vício de informação na atividade médica, e inicia relembrando os dois principais objetivos do dever de informação do fornecedor: capacitar o consumidor para que ele tome uma decisão livre sobre qual produto quer comprar ou qual serviço quer contratar, e maximizar o proveito do produto ou serviço com a maior segurança. O autor explica que pelo princípio da autodeterminação do consumidor, o paciente deve ter toda a informação disponível ao fornecedor para que sua decisão seja tomada livre e conscientemente. No entanto, lembra que são cinco as exceções a esse dever de informação: o interesse público (emergências de saúde pública), situações de urgência ou emergência médicas, paciente incapaz (pacientes menores de idade ou inconscientes, o que não exime o 
profissional de buscar, quando possível, autorização dos responsáveis), paciente que expressa e conscientemente abdica do direito a uma informação mais precisa sobre o procedimento, o privilégio terapêutico (nesse caso, o médico poderia omitir informações quando entendesse que o conhecimento delas pelo paciente pode colocar sua saúde em risco - o autor defende que essa possibilidade seja usada somente em situações excepcionais e muito bem justificada, para que não fique sujeita a abusos sobre a autonomia do paciente). A última questão tratada no capítulo diz respeito à prova. $\mathrm{O}$ autor questiona, com propriedade, como se faz e a quem cabe fazer a prova de que o procedimento médico foi precedido de consentimento esclarecido do paciente. Defende uma solução intermediária, qual seja, "não obrigar o fornecedor a obter o consentimento do paciente sempre por escrito, analisando-se, em cada caso, as circunstâncias relevantes, como a gravidade do procedimento, a relação entre riscos e benefícios esperados, para se concluir se, no balanço das probabilidades, o consentimento foi obtido ou não".

O estudo de Octávio Luiz Motta Ferraz é muito pertinente por trazer à luz uma discussão de extrema relevância para a população brasileira, e principalmente para aqueles consumidores que possuem algum tipo de relação de consumo com as empresas privadas da área médica. Traz conceitos, discussões e exemplos que permitem ao leitor entender, de forma clara, o entendimento do autor com relação à responsabilidade civil das empresas que atuam na área médica: para configuração da responsabilidade, é imprescindível a constatação de um defeito no produto ou no serviço. Se esse defeito depende do estágio de desenvolvimento da técnica e da ciência, por conseguinte a responsabilização das empresas também será condicionada a essas mesmas variáveis. A principal conclusão a que chega o autor é que as empresas estão sujeitas às normas de responsabilidade civil previstas no Código de Defesa do Consumidor, mas essa responsabilidade poderá ser mais subjetiva ou mais objetiva, a depender do caso concreto e do tempo histórico. 